\title{
Improvement of production facilities for improving the sales of banana crafts managers and improving production facilities for improving the sales of banana crafts and peek crafts
}

\author{
Idhar Yahya $^{1 *}$, Khawarita Siregar ${ }^{2}$ \\ ${ }^{1}$ Departemen Akuntansi, Fakultas Ekonomi dan Bisnis, Universitas Sumatera Utara \\ ${ }^{2}$ Departemen Teknik Industri, Fakultas Teknik, Universitas Sumatera \\ *Email : idhar@usu.ac.id
}

\begin{abstract}
The business of making chips has two main products namely peyek chips and banana chips. Making peyek chips and banana chips is done manually using a very simple production facility. The process of frying chips requires a long time because the craftsman only has 1 stove and 1 pan so that the frying process is carried out alternately between peyek and banana chips. This has an impact on a limited quantity of projects so that often customer requests cannot be fulfilled. The quality of chips produced sometimes does not satisfy consumers because it is not crispy if stored for a period of time. This is because the crafters use thin plastic and the process of adhesion to the packaging activities is carried out using candles and kerosene lamps. In addition to not sticking to plastic, there is also a hollow plastic package so that air can get into the chips. The dedication team provided solutions to increase production in the form of 2 units of high pressure cookers, 1 unit of furnace, 3 units of iron frying pan, 1 unit of plastic packaging adhesive (sealer), 1 unit of mechanical sweet potato slicer, 1 unit of semimechanical banana slicer, procurement brands and thick plastic. Utilization of these production facilities results in the addition of the types of products produced, namely tojin beans, sweet potato chips, pan flowers and rengginang. Increasing the quality and quantity of products has an impact on increasing the market so that it has been marketed to simple housing, medium housing complexes and now modern outlets are willing to accept the products produced.
\end{abstract}

Keywords: Production facilities, Increased sales, Peik chips, Banana chips

\begin{abstract}
Abstrak
Usaha pembuatan keripik memiliki dua produk utama yaitu keripik peyek dan keripik pisang. Pembuatan keripik peyek dan keripik pisang dilakukan secara manual menggunakan fasilitas produksi yang sangat sederhana. Proses penggorengan keripik membutuhkan waktu yang lama karena perajin hanya memiliki 1 kompor dan 1 wajan sehingga proses penggorengan dilakukan secara bergantian antara keripik peyek dan pisang. Hal ini berdampak pada kuantitas peyek yang terbatas sehingga sering permintaan pelanggan tidak dapat dipenuhi. Kualitas keripik yang dihasilkan terkadang tidak memuaskan konsumen karena tidak renyah jika disimpan selama bebarapa waktu. Ini disebabkan perajin menggunakan plastik yang tipis dan proses perekatan pada kegiatan pengemasan dilakukan dengan menggunakan lilin dan lampu teplok. Selain tidak melekatnya plastik juga adanya kemasan plastik yang berlubang sehingga memungkin udara masuk ke dalam kemasan keripik. Tim pengabdian memberikan solusi untuk peningkatan produksi berupa 2 unit kompor high pressure, 1 unit tungku, 3 unit wajan penggorengan besi, 1 unit alat perekat kemasan plastik (sealer), 1 unit alat pengiris ubi mekanis, 1 unit alat pengiris pisang semi mekanis, pengadaan merk dan plastik tebal. Pemanfaatan fasilitas produksi tersebut menyebabkan terjadi penambahan jenis produk yang dihasilkan yaitu kacang tojin, keripik ubi, kembang loyang dan rengginang. Peningkatan kualitas dan kuantitas produk berdampak pada meningkatnya pasar sehingga sudah dipasarkan ke perumahan sederhana, komplek perumahan menengah dan kini gerai modern telah bersedia menerima produk yang dihasilkan.
\end{abstract}

Kata kunci : Fasilitas produksi, Peningkatan penjualan, Keripik peyek, Keripik pisang 


\section{PENDAHULUAN}

Usaha mikro sangat bermanfaat bagi masyarakat karena menjadi tempat untuk bekerja dan menyambung hidup sehingga sangat berperan dalam pembangunan ekonomi nasional. Usaha mikro merupakan tempat bergantung masyarakat dengan penyerapan tenaga kerja yang demikian besar sehingga merupakan motor pertumbuhan aktivitas ekonomi. Pembinaan dan pengembangan usaha mikro yang baik akan memperbesar sumbangannya bagi perekonomian nasional pada umumnya dan memberikan sumbangan bagi daerah dimana usaha mikro itu tumbuh dan berkembang. Di samping berperanan besar dalam menyerap tenaga kerja, usaha mikro juga berperan dalam meningkatkan penghasilan masyarakat dan meningkatkan ekspor. Bantuan dan upaya peningkatan usaha mikro dan menengah dalam perekonomian nasional melalui pembinaan yang mencakup permodalan seperti kredit untuk usaha kecil dan menengah, bantuan teknologi dan informasi, pengembangan sumberdaya manusia dan pemasarannya. Ketiadaan dukungan merupakan kendala perkembangan usaha kecil seperti akses terhadap teknologi dan peningkatan sumber daya manusia. Tujuan akhir dari usaha ini adalah meningkatkan kesejahteraan masyarakat kalangan bawah yang kurang beruntung pada khususnya dan masyarakat luas pada umumnya (Tambunan, 2011).

Mitra pada kegiatan pengabdian ini adalah usaha keripik Asih dengan 3 orang perajin yang melakukan kegiatan pembuatan keripik mulai dari mempersiapkan bahan baku hingga mendistribusikan keripik pada pelanggan. Usaha keripik Asih terletak di Kecamatan Hinai, Desa Perkebunan Tanjung Beringin, Kabupaten Langkat. Kecamatan Hinai dulu dikenal sebagai daerah kekuasaan Sultan Langkat yang dipimpin oleh Datok Cempa dengan pusat penduduk kebanyakan di wilayah Batu Melenggang. Wilayah ini merupakan jalan lintas provinsi antara Provinsi Aceh dan Provinsi Sumatera Utara. Banyak Usaha pengrajin keripik dan sejenis dilakukan oleh masyarakat di wilayah ini sebagai bagian dari pemberdayaan ekonomi keluarga secara berkelanjutan.

Usaha keripik Asih memiliki dua produk utama yaitu keripik peyek dan keripik pisang sebagaimana terlihat di Gambar-1.1 (Sarastri Mumpuni, 2013). Proses pembuatan keripik peyek dimulai dari menyiapkan bahan baku (tepung, telur, kacang, penyedap, minyak goreng), mencampur bahan baku, mengaduk adonan, menyiapkan penggorengan, menggoreng keripik peyek, mengeringkan keripik peyek dari minyak, menyimpan hingga membungkus keripik peyek (Winarno, Muniya Alteza, Lina Nur Hidayati, 2013). Sedangkan proses pembuatan keripik pisang dimulai dari mengupas kulit pisang, mencuci pisang, mengiris dan menggoreng pisang, mengeringkan keripik pisang dari minyak hingga proses pengemasan keripik pisang (Ndaguba, Nzewi, Ijeoma, Sambumbu, \& Sibanda, 2018).
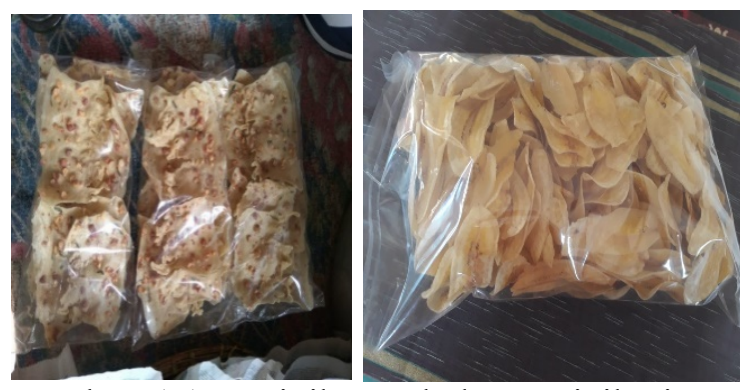

Gambar 1.1. Keripik Peyek dan Keripik Pisang

Proses pembuatan keripik seluruhnya dilakukan secara manual dengan peralatan yang sangat terbatas. Hal ini menyebabkan perajin merasakan kaku dan agak sakit pada beberapa anggota tubuh (Jones, 2015).

Penggorengan keripik menggunakan wajan berdiameter $55 \mathrm{~cm}$ dengan kompor 1 tungku berdimensi $25 \mathrm{~cm} \times 37 \mathrm{~cm} \times 9 \mathrm{~cm}$. Proses Pembuatan keripik peyek dan keripik pisang harus 
dilakukan secara bergantian karena peralatan memasak yang terbatas sementara untuk menyelesaikan satu produk keripik memerlukan waktu lebih kurang 4-5 jam sehingga untuk menyelesaikan keripik pisang dan keripik peyek memerlukan waktu mencapai 9 jam. Pada Gambar 1.2 terlihat fasilitas kerja yang digunakan pada proses pembuatan keripik peyek dan keripik pisang.

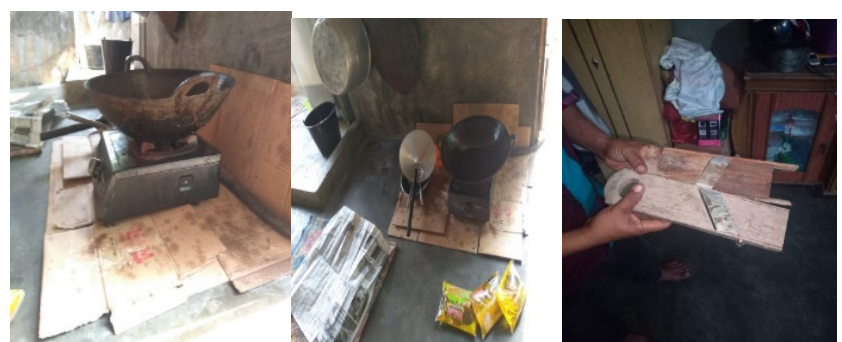

Gambar 1.2. Fasilitas Kerja Perajin Keripik

Wajan yang digunakan untuk menggoreng keripik peyek hanya dapat memuat 8 potongan peyek untuk setiap kali menggoreng dengan waktu 4 menit. Proses pencetakan keripik peyek dilakukan secara manual dengan menggunakan sebuah sendok plastik. Bahan baku tepung $4 \mathrm{~kg}$ dapat diselesaikan dalam 60 kali proses pencetakan dan menghasilkan 28 bungkus keripik peyek yang siap untuk dipasarkan. Proses pembuatan keripik peyek terdapat pada Gambar 1.3.

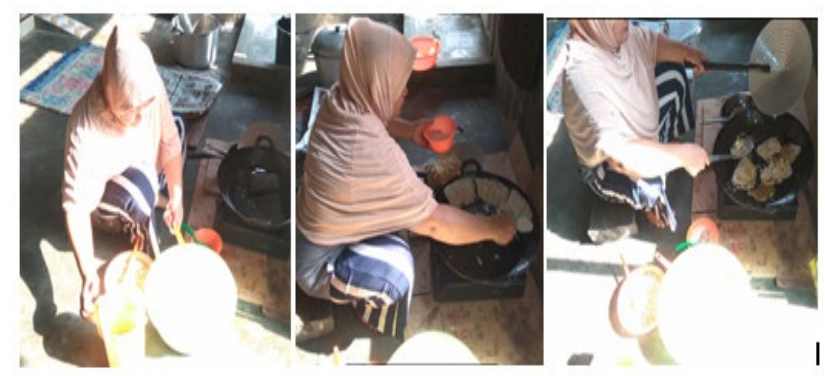

Gambar 1.3.Proses Pembuatan Keripik Peyek

Kegiatan produksi keripik pisang juga dilakukan dengan menggunakan kompor, tungku dan wajan yang sama karena keterbatasan peralatan. Dalam 1 hari usaha keripik Asih dapat menghabiskan bahan sebanyak 2 tandan pisang. Proses pertama untuk membuat keripik pisang adalah mengupas pisang, pencucian pisang dan perajangan secara manual. Proses perajangan dilakukan langsung diatas kompor satu per satu hingga kuali terisi penuh dengan irisan pisang. Kegiatan perajangan pisang secara manual berbahaya karena pekerja harus menggerakkan pisang maju mundur secara berulang pada sebilah papan yang dilengkapi mata pisau yang tajam langsung diatas wajan berisi minyak panas (Gambar 1.4).

Hal ini menyebabkan diperlukan adanya perancangan alat yang digunakan sehingga dapat menghindari terjadinya kecelakaan yang akan menimpa perajin saat proses produksi (Anizar, 2015)(Widyastuti, Torong, \& Hariyono, 2017).

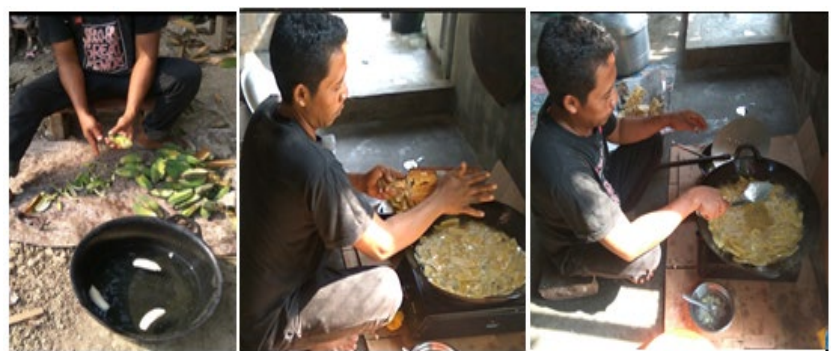

Gambar 1.4.Proses Penggorengan Keripik Pisang 
Keripik peyek dan pisang hanya dapat dipasarkan 2 hari sekali karena proses produksi dan penjualan dilakukan sendiri. Alat bantu yang dipergunakan dalam menghasilkan keripik juga sangat sederhana dan tidak cukup untuk menampung hasil produksi. Hal ini menyebabkan setelah selesai digoreng maka perajin harus segera memasukkan keripik peyek dan keripik pisang ke dalam kemasan. Proses pengemasan produk dilakukan secara manual menggunakan api dari lampu teplok sebagaimana ditampilkan pada Gambar 1.5.

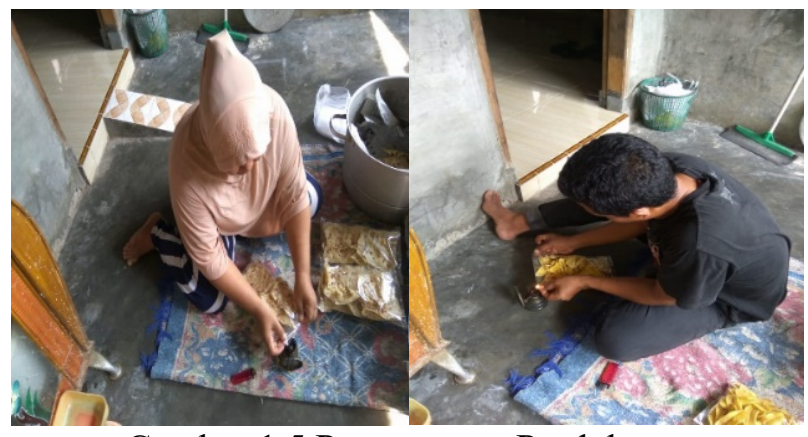

Gambar 1.5.Pengemasan Produk

\section{METODE PELAKSANAAN}

Metode pelaksanaan pada kegiatan pengabdian ini merupakan pendekatan permasalahan produksi. Hal tersebut dimulai dari melakukan pengamatan awal terhadap kegiatan proses produksi secara keseluruhan. Kemudian melakukan diskusi dengan perajin keripik terhadap pelaksanaan produksi selama ini. Tim menjelaskan solusi dan akan menerapkan solusi tersebut dengan mempertimbangkan masukan dari perajin keripik (Gambar 2.1).

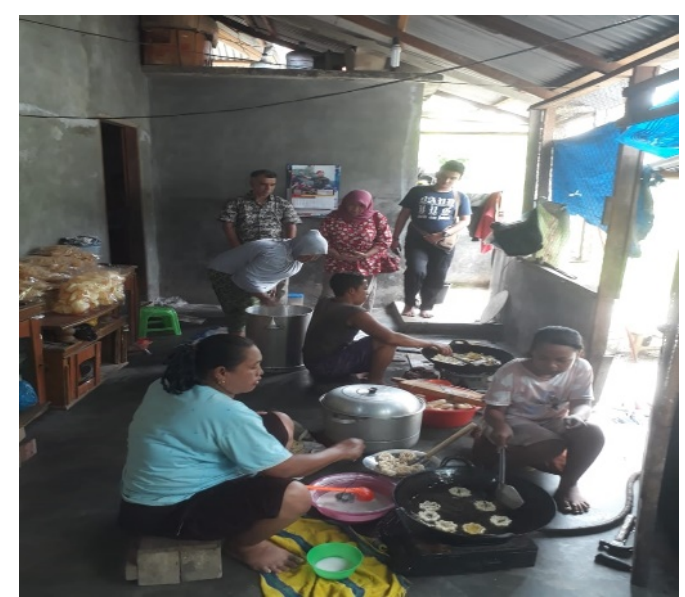

Gambar 2.1. Proses Produksi Keripik

Secara rinci metode pelaksanaan adalah sebagai berikut :

1. Menganalisis fasilitas dan peralatan yang digunakan dalam proses produksi keripik.

2. Pengadaan perbaikan fasilitas dan peralatan kerja seperti kuali, kompor, dan alat perekat plastik.

3. Penggunaan fasilitas kuali, kompor, dan alat perekat pastik yang baru.

4. Perancangan dan pengadaan alat pengiris pisang semi mekanis dan alat pengiris ubi mekanis.

5. Penggunaan alat pengiris pisang semi mekanis dan alat pengiris ubi mekanis. 
6. Pendampingan pemakaian alat pengiris pisang semi mekanis, alat pengiris ubi mekanis beserta perlengkapan fasilitas dan barang produksi.

\section{HASIL DAN PEMBAHASAN}

Pengadaan fasilitas kerja yang diberikan oleh tim pengabdian menyebabkan perajin keripik dapat melakukan proses produksi secara bersamaan (Krause \& Scherzer, 2005). Dengan demikian produk yang dihasilkan lebih banyak dengan waktu pengerjaan lebih singkat (Gambar 3.1).

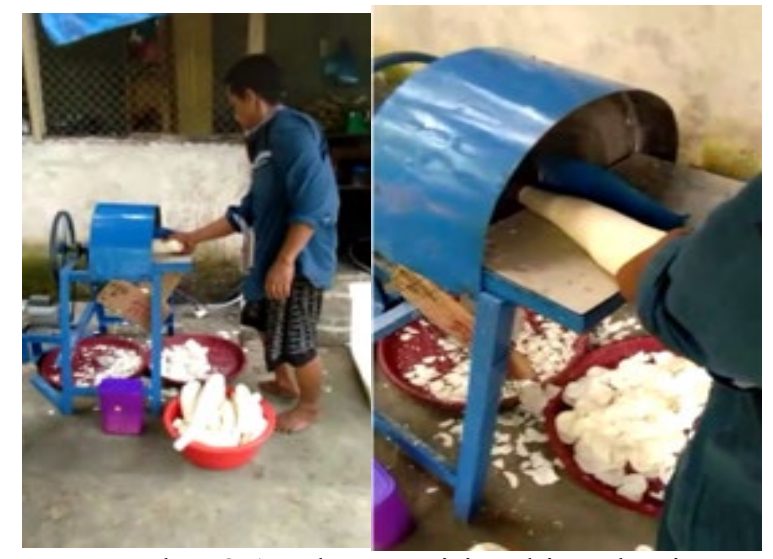

Gambar 3.1. Alat Pengiris Ubi Mekanis

Bantuan tungku kayu mempermudah proses penggorengan keripik ubi sehingga keripik ubi yang dihasilkan lebih renyah (Gambar 3.2).

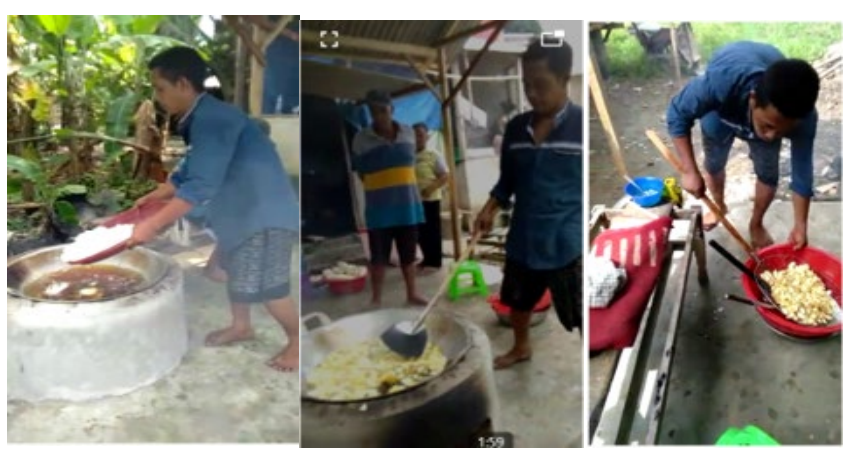

Gambar 3.2. Proses Penggorengan Keripik Ubi 


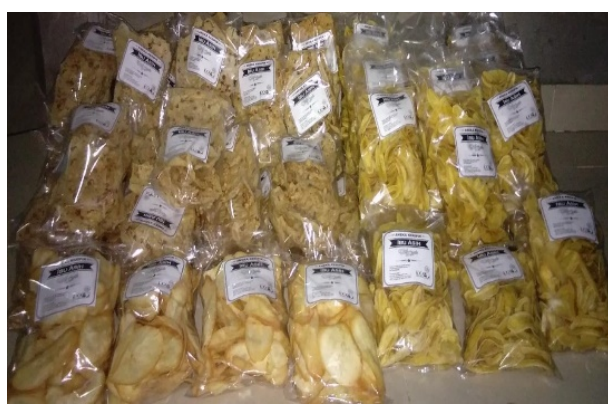

Gambar 3.3. Kemasan dengan merk

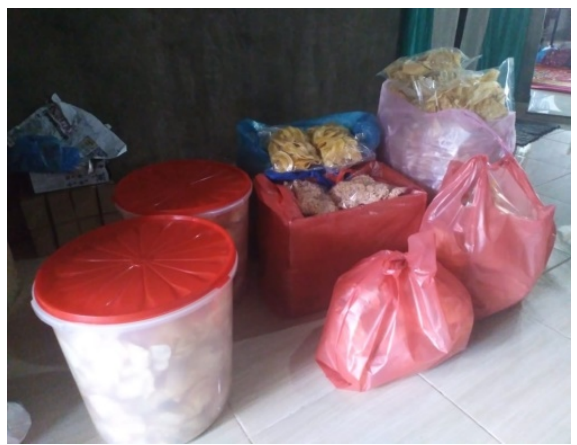

Gambar 3.4. Produksi Keripik Siap Edar

\section{KESIMPULAN}

Pengabdian yang dilakukan ini pada jangka pendek akan meningkatkan kualitas dan kuantitas keripik yang dihasilkan oleh perajin. Sedangkan dalam jangka panjang akan meningkatkan kinerja perajin sehingga akan meningkatkan tingkat pendapatan perajin keripik dengan bertambahnya produk yang dihasilkan.

\section{UCAPAN TERIMAKASIH}

Ucapan terima kasih disampaikan kepada Rektor Universitas Sumatera Utara atas dana non PNBP USU TA 2019 yang diberikan dengan nomor kontrak 321/UN5.2.3.2.1/PPM/2019. Terima kasih juga disampaikan kepada mitra pada kegiatan pengabdian ini yaitu perajin keripik Asih yang telah bersedia bekerja sama.

\section{DAFTAR PUSTAKA}

Anizar. (2015). Analisis Desain Tojok Sebagai Alat Sortasi TBS Kelapa Sawit di Loading Ramp. Jurnal Teknik Industri, X(3), 149-154.

Jones, D. R. (2015). The Relationship Between Working Conditions and Musculoskeletal/Ergonomic Disorders in a Manufacturing Facility - A Longitudinal Research Study. Procedia Manufacturing, 3(Ahfe), 4480-4484. https://doi.org/10.1016/j.promfg.2015.07.461 
Krause, N., \& Scherzer, Ã. T. (2005). Physical workload, work intensification, and prevalence of pain in low wage workers: results from a participatory research project with hotel room cleaners in Las Vegas. Am J Ind Med 2005;48:326-337.CrossRefMedline, 337, 326-337. https://doi.org/10.1002/ajim.20221.

Ndaguba, E. A., Nzewi, O. I., Ijeoma, E. C., Sambumbu, M., \& Sibanda, M. M. (2018). Using Taylorism to make work easier: A work procedure perspective. South African Journal of Economic and Management Sciences,21(1),1-10. https://doi.org/10.4102/sajems.v21i1.2120

Sarastri Mumpuni, I. P. P. (2013). Pelatihan penyempurnaan produk peyek rebon, 2(3), 154-157.

Tambunan, T. T. H. (2011). Development of micro, small and medium enterprises and their constraints: A story from Indonesia. Gadjah Mada International Journal of Business, 13(1), 21-43.

Widyastuti, D. E., Torong, M. Z. B., \& Hariyono, K. (2017). Perbaikan Disain Alat Pencacah Pelepah Sawit untuk Mengurangi Keluhan Sakit Peternak Sapi, 2017, 4-6.

Winarno, Muniya Alteza, Lina Nur Hidayati, A. D. (2013). Optimalisasi Pengelolaan Usaha Pengrajin Peyek Melalui Peningkatan Kompetensi Manajerial, 1-15. 